\title{
La naturalización de los mercaderes franceses de Cádiz a finales del siglo XVIII y principios del XIX ${ }^{1}$
}

\author{
Arnaud BARTOLOMEI \\ Maître de conférences \\ Département d'Histoire \\ Université de Nice-Sophia Antipolis - CMMC \\ Francia \\ bartolomei@unice.fr
}

Fecha de recepción: 24/05/2011

Fecha de aceptación: 15/12/2011

\section{RESUMEN}

La cuestión de la naturalización de los mercaderes extranjeros en Cádiz se enfrenta a una extraordinaria paradoja: mientras que los privilegios accesibles gracias a la naturalización eran considerables -puesto que permitían nada menos que acceder con toda legalidad al muy codiciado comercio colonial español y a sus fabuleux métaux - el número de cartas de naturaleza otorgadas en la ciudad a lo largo del siglo XVIII es muy reducido ${ }^{2}$, e incluso desdeñable si se compara con la importancia numérica de las colonias de comerciantes extranjeros: a fines del XVIII, los extranjeros representaban aproximadamente el 10\% de la población de la ciudad ${ }^{3}$ y un mercader de cada dos no era español ${ }^{4}$. Por lo tanto, ese desfase lleva a la siguiente pregunta: ¿por qué los mercaderes extranjeros, a pesar de ser reputados por su oportunismo y su utilitarismo, no buscaron adquirir una nacionalidad que les hubiera garantizando tantas ventajas?

Palabras clave: extranjeros, comercio, franceses, naturalización, Cádiz, siglos XVIII-XIX.

\footnotetext{
1 Traducción de Thomas Glesener, revisada por el autor. Título original: La naturalisation des marchands français de Cadix à la fin du XVIIIe siècle et au début du XIXe siècle.

2 En el siglo XVIII el Consejo de Indias otorgó 76 cartas de naturaleza a extranjeros para comerciar con Indias. De éstas, 29 fueron concedidas a genoveses, 15 a irlandeses, 11 a franceses, 5 a flamencos y 5 a portugueses: HEREDIA Herrera, Antonia: «La presencia de extranjeros en el comercio gaditano en el siglo XVIII», en Homenaje a Dr. Muro Orejón, Sevilla, Facultad de Filosofía y Letras, 1979, vol. 1, pp. 235-243.

3 El número de extranjeros en Cádiz inscritos en la matrícula de extranjeros de 1791 se eleva, según Collado Villalta, a 5.020 -de los cuales 1.598 eran franceses-, es decir un 7\% de la población de la ciudad: CoLLADO ViLLALTA, Pedro: «El impacto americano en la Bahía: la inmigración extranjera en Cádiz, 1709-1819», en Primeras Jornadas de Andalucía y América de la Rábida, Huelva, Instituto de Estudios Onubenses, 1981, vol. 1, pp. 49-73. Es verosímil que esta cifra estuviese por debajo de la realidad, puesto que bastantes extranjeros -franceses en particular-, habían salido de la ciudad antes de que se iniciase la matrícula. Por otra parte, un número mucho más alto de extranjeros no se presentaron a las autoridades puesto que se creían perfectamente españoles y no se consideraban afectados por esa medida.

4 Bustos Rodríguez, Manuel: Los comerciantes de la Carrera de Indias en el Cádiz del siglo XVIII, Cádiz, Servicio de publicaciones de la Universidad de Cádiz, 1995.
} 


\title{
The Spanish Naturalization of French merchants in Cadiz in the Late Eighteenth and Early Nineteenth Centuries
}

\begin{abstract}
The issue of Spanish naturalization of foreign merchants in Cadiz faces to an extraordinary paradox: while access to privileges through naturalization guaranteed many advantages -including a free, legally access to Spanish colonial trade and its fabuleux métaux - the number of cartas de naturaleza issued in Cadiz throughout the eighteenth century is quite small, and even negligible if compared to the numerical importance of foreign merchants communities in the city: in the late eighteenth century, foreigners accounted for approximately $10 \%$ population of Cadiz and a merchant of two was not Spanish. Therefore, this discrepancy raises the following question: why foreign merchants, despite being renowed for their opportunism and utilitarianism did not seek to acquire the Spanish nationality that would guarantee them so many advantages?
\end{abstract}

Key words: foreigners, trade, naturalization, French community, Cadiz, $18^{\text {th }}$ and $19^{\text {th }} \mathrm{C}$.

\section{INTRODUCCIÓN}

La historiografía sobre el comercio de Cádiz ha propuesto dos interpretaciones a la paradoja arriba señalada. Ciertos autores han subrayado el empeño con el cual los actores locales del comercio defendieron sus privilegios contra toda intrusión extranjera. Esto ha sido demostrado particularmente a través del estudio del proceso que hicieron los cargadores -los negociantes españoles habilitados a cargar las mercancías para Indias-, a través del Consulado, contra los famosos jenízaros -los hijos de mercaderes extranjeros nacidos en España que, como tales, podían teóricamente pretender legítimamente los mismos derechos que los demás españoles ${ }^{5}$. $\mathrm{Si}$, en la práctica, los cargadores fracasaron en su intento de cerrar la carrera de Indias a estos hijos de extranjeros, las cuatro décadas que duró el proceso demuestran con qué vigilancia velaron por la defensa de sus privilegios. Otros autores han explicado, al contrario, el poco interés mostrado por los mercaderes extranjeros de Cádiz en la naturalización, debido a la importancia de los privilegios que ya disfrutaban: al beneficiarse en particular de inmunidades jurídicas muy importantes, esos mercaderes habrían tenido más ventaja en introducirse ilegalmente en la carrera de Indias - usando especialmente testaferros- en lugar de hacerlo legalmente, esto es, solicitando la naturalización oficial ${ }^{6}$. Recientemente, Catia Brilli ha contribuido ampliamente a renovar este debate, estudiando en su tesis un caso particular: la colonia genovesa de Cádiz. Brilli demuestra efectivamente que los mercaderes genoveses fueron una excepción a la regla, puesto que siguieron una vía diferente a las demás colonias extranjeras de la ciudad, privilegiando una estrategia de integración con la población local -basada precisamente en la adquisición de cartas de naturaleza-, por no poder contar con el apoyo de un potente estado mercantilista

\footnotetext{
5 García-Mauriño Mundi, Margarita: La pugna entre el Consulado de Cádiz y los jenízaros por las exportaciones a Indias (1720-1765), Sevilla, Universidad de Sevilla, 1999.

6 La mejor síntesis sobre los privilegios de los mercaderes extranjeros radicados en Andalucía sigue siendo la de Girard, Albert: Le commerce français à Séville et à Cadix au temps des Habsbourg. Contribution à l'étude du commerce des étrangers en Espagne aux XVIe-XVIIe siècles, París, E. de Boccard, 1932.
} 
(como Francia, Reino Unido o las Provincias Unidas) para proteger sus prácticas comerciales ilícitas ${ }^{7}$.

Aparte de las divergencias entre esas diferentes interpretaciones, se debe subrayar que todas están de acuerdo en un punto: el utilitarismo compartido por todos los protagonistas de la época. En efecto, los mercaderes extranjeros habrían desarrollado estrategias coherentes en términos de integración y de naturalización, evaluando las ventajas y los inconvenientes de cada opción y determinándose por la solución más ventajosa. En cuanto a los actores de la sociedad de acogida, también habrían actuando según lógicas similares: el Estado, manifestando interés sólo por los extranjeros susceptibles de ser considerados como sujetos "útiles"; y los mercaderes esforzándose por limitar el acceso a sus privilegios. Tal interpretación no es exclusiva de la situación del comercio en Cádiz ni a la del comercio colonial español en general, puesto que, de manera más amplia, se encuentran elementos de una visión utilitarista de las decisiones de los actores implicados en las prácticas de naturalización en toda la historiografía dedicada al tema ${ }^{8}$. Además, la experiencia de los mercaderes franceses de Cádiz a fines del XVIII parece a primera vista confirmar la hipótesis utilitarista: mientras se habían desinteresado de la naturalización a lo largo del siglo -en una época en la cual la protección ofrecida por sus privilegios les permitía practicar el comercio en condiciones ventajosas-, fueron cada vez más numerosos los franceses que la solicitaron a partir de la Revolución de 1789, cuando el estatuto de francés empezó a ser una limitación para comerciar en España.

Los recientes trabajos de la historiadora americana Tamar Herzog, dedicados al estudio de la condición de extranjero en España han demostrado, sin embargo, que los mecanismos que rigen los procesos de integración y de naturalización no se prestan siempre a una lectura tan lineal. Más que tratarse de "sujetos útiles" o "ricos", el estado español -sin descuidar estos dos criterios o los intereses particulares de los grupos influyentes a los cuales pertenecían-, habría buscado antes que nada naturalizar a los individuos perfectamente integrados en la sociedad española, que compartían la vida cotidiana de las comunidades locales donde residían y donde eran reconocidos como miembros plenos y de derecho ${ }^{9}$. De igual modo, los

\footnotetext{
7 Brilli, Catia: La diaspora commerciale ligure nel sistema atlantico iberico. Da Cadicce a Buenos Aires (17501830), tesis doctoral inédita, Universidad de Pisa, 2008. Las conclusiones son presentadas en «Mercaderes genoveses en el Cádiz del siglo XVIII. Crisis y reajuste de una simbiosis secular», en Crespo SolanA, A. (dir.): Comunidades transnacionales. Colonias de mercaderes extranjeros en el Mundo Atlántico (1500-1830), Madrid, Doce Calles, 2010, pp. 83-102.

8 Ver la introducción al libro BotTin, Jacques y CALABI, Donatella (dir.): Les étrangers dans la ville. Minorités et espace urbain du bas Moyen Âge à l'époque moderne, París, Maison des Sciences de l'homme de Paris, 1999: «En Rouen, Londres o Burdeos, son principalmente las ventajas materiales vinculadas al nuevo estatuto las que determinaban, como en Venecia, a los actores económicos de alto nivel a solicitarlo más que otros» (p. 6). En el mismo libro, Reinhold C. Mueller constata también que «los motivos por los cuales un inmigrante intenta obtener el privilegio de la ciudadanía veneciana son básicamente de orden económico»: Mueller, R.C.: «Veneti facti privilegio: les étrangers naturalisés à Venise entre XIV et XVI ${ }^{\mathrm{e}}$ siècle», p. 172. Peter Shalins confirma esta opinión al argumentar que «todas las demandas de naturalización en el Antiguo Régimen son interesadas: los extranjeros pretendientes a la naturalización esperan escapar a las cargas fiscales de su estatuto»: SHALins, P.: «La nationalité avant la lettre. Les pratiques de naturalisation en France sous 1'Ancien Régime», Annales. Histoire, Sciences Sociales, 55/5 (2000), p. 1091.
}

9 Herzog, Tamar: Vecinos y extranjeros: hacerse español en la Edad moderna, Madrid, Alianza Editorial, 2006. 
pretendientes que solicitaban cartas de naturaleza no se guiaban necesariamente por el deseo de conseguir una ventaja particular de la cual estaban excluidos, sino simplemente por la voluntad de verse reconocidos -en un contexto en el que este reconocimiento era importante para ellos-, una situación de hecho en la cual ya estaban. Desde esta perspectiva, el procedimiento de naturalización ya no aparece como una cuestión sistemáticamente instrumentalizada por el Estado, por los miembros de la sociedad de acogida o por los propios extranjeros con el fin de adquirir o limitar el recorte a sus derechos y privilegios, sino como un mecanismo que venía a oficializar -aunque no sea en toda objetividad, al menos de manera más neutral-, situaciones de hecho empíricamente comprobadas.

Con esta nueva aportación hemos querido retomar la cuestión de la naturalización de los mercaderes franceses en Cádiz a fines del XVIII e interrogarnos por el cambio de actitud que se observa a partir de la Revolución francesa. Hemos recurrido para ello a dos corpus de fuentes distintas que nos informan tanto de los intereses de los mercaderes extranjeros que solicitaron su naturalización, como de los intereses defendidos por la administración española. Por un lado, una amplia investigación prosopográfica, realizada en nuestra tesis ${ }^{10}$, nos permite acercarnos a las trayectorias, prácticas sociales y estrategias comerciales de unos 500 mercaderes franceses presentes en Cádiz durante la década de 1790; por otro lado, documentación diversa y en parte inédita -cartas y expedientes de naturalización, correspondencia administrativa- arroja luz sobre el desarrollo concreto de los procedimientos de naturalización en el Cádiz del XVIII y sobre lo que está en juego con ellos. Tras un rápido repaso de los diferentes estatutos jurídicos propuestos a los extranjeros en la España moderna, analizaremos el procedimiento de naturalización y su desarrollo, antes de volver, a partir de las conclusiones sacadas, a los motivos de los mercaderes franceses para solicitar o no su naturalización en un contexto tan particular como el periodo revolucionario.

\section{LOS ESTATUTOS DE LOS EXTRANJEROS EN CÁDIZ A FINES DEL XVIII: LOS ENGAÑOS DE LA CONFUSIÓN}

En apariencia, los estatutos definitorios de la condición de los extranjeros en el comercio de Cádiz -y más globalmente en España- eran mucho más numerosos, y el marco jurídico de conjunto que los delimitaba mucho más complejo, que la situación que conocemos hoy, donde en definitiva sólo existen dos categorías: los nacionales y los extranjeros. En efecto, los extranjeros podían ser auténticos extranjeros en sentido propio, es decir transeúntes, y beneficiarse por lo tanto de la protección de su cónsul y de los privilegios obtenidos por su país de origen; pero también podían ser avecindados -o domiciliados-, es decir, un estatuto que les llevaba a renunciar a dicha protección y a prestar juramento a la corona española, sin

10 Bartolomei, Arnaud: La Bourse et la vie. Destin collectif et trajectoires individuelles des marchands français de Cadix de l'instauration du comercio libre à la disparition de l'empire espagnol (1778-1824), tesis doctoral, Universidad de Provenza, 2007. 
acceder por tanto a todos los derechos inherentes a la naturaleza española. La situación era igualmente compleja para los extranjeros naturalizados españoles, puesto que sólo los que habían obtenido una carta de naturaleza para comerciar con Indias, concedida por el Consejo de Indias, podían beneficiarse de la totalidad de los derechos disfrutados por el resto de los súbditos españoles, mientras que los que habían obtenido su carta de naturaleza del Consejo de Castilla sólo les daba acceso a una ciudadanía limitada, estando excluídos del comercio colonial, del derecho a poseer salinas y de acceder a ciertos beneficios eclesiásticos ${ }^{11}$. Por último, los hijos de los mercaderes extranjeros, aunque hubieran nacido en Cádiz y hubieran debido, en teoría, ser considerados como naturales españoles, sufrían también ciertas restricciones -aunque hubieran ganado la causa contra el Consulado que quería limitarles el acceso al comercio colonial. El caso de los hermanos Behic, que no pudieron obtener su habilitación por haberse quedado su padre matriculado en el consulado de Francia, es famoso. Otro caso, como el de Josef Eugenio Lassaleta, que tuvo que esperar a que su padre disolviera su asociación con un socio extranjero para obtener su habilitación, confirma que a finales de siglo la habilitación para comerciar con Indias aún no era atribuida automáticamente a los jenízaros ${ }^{12}$. Son, por tanto, nada menos de cuatro estatutos -domiciliado, naturalizado, naturalizado con licencia y jenizaro- los que se interponían entre el estatuto de extranjero (transeúnte) y el de español (natural de estos reinos).

Sin embargo, sería un error considerar esta pluralidad de estatutos como un signo de la confusión dominante en las instituciones que regían la condición de extranjeros en la España moderna. Cada uno de esos estatutos, en efecto, se refería a un corpus de textos y de prácticas jurídicas que definían los criterios que permitían el acceso al codiciado estatuto, las prerrogativas a las cuales otorgaba derecho, como los actores y las organizaciones encargadas de velar al respecto de los reglamentos (el Consejo de Castilla, el de Indias...). Eso no significa naturalmente que no haya habido, a lo largo del siglo XVIII, conflictos en la definición y la aplicación de esos estatutos, así como evoluciones en la legislación que los organizaban. El estatuto de domiciliado, por ejemplo, fue formalizado en 1716, pero no fue realmente aplicado sistemáticamente, tras varios intentos fallidos, hasta el censo de 1791, antes de caer inmediatamente en desuso ${ }^{13}$. El estatuto de jenizaro evolucionó también a lo largo del siglo en función de las relaciones de poder. Asímismo, no hay duda de que haya podido haber, al margen, individuos que se hayan encontrado en situación de aprovechar esta pluralidad de estatutos para presentarse bajo uno u otro en función de los intereses del momento. Evidentemente, estos casos han existido, pero nos parece abusivo considerarles como la norma, como ha sido frecuentemente

11 Archivo Municipal de Cádiz (en adelante AMC), Libros de Actas Capitulares (LAC), Libro 154, f. 233, registro de la carta de naturaleza de Lorenzo Sorhaits (22 de agosto de 1798).

12 Archivo General de Indias (AGI), Indiferente General (ID), leg. 1537, «Expediente sobre concesión de carta de naturaleza a Don Josef Eugenio Lassaleta del comercio de Cádiz» (1790). En realidad, el compromiso que salió de la causa intentada por el Consulado preveía que un jenízaro no podía obtener su habilitación sólo bajo la condición de que su padre no estuviera matriculado en un consulado de su país de origen. Sobre el caso de los hermanos Behic: Herzog: op. cit. (nota 9), p. 162.

13 Ver nota 14. 
hecho, o incluso como una actitud frecuente entre los mercaderes ${ }^{14}$. A pesar de la persistencia de algunas zonas intermediarias, mal delimitadas, el derecho de los extranjeros en la España moderna era complejo, más que confuso y, de forma general, perfectamente operativo.

Evidentemente, en el comercio de Cádiz no todo el mundo sabía, exactamente, quién era quién. Hay que notar sin embargo que, en la práctica, pocos individuos accedían abiertamente a derechos o prerrogativas que su estatuto les prohibía. Las listas que fueron establecidas, con el fin de dividir a los extranjeros entre los distintos estatutos existentes, eran por cierto siempre muy parciales y, hasta el gran censo de los extranjeros de 1791, no tuvo éxito ninguna tentativa de matricular separadamente a transeúntes y avecindados ${ }^{15}$. Así, no es de extrañar que muchos franceses no se presentasen a la convocatoria de juramento de 1791, puesto que estaban persuadidos, en toda sinceridad, de ser realmente españoles y que, por lo tanto, tal juramento no les concernía: avecindados de hecho, por su larga estancia en la Península, de su matrimonio con una española o de la ausencia de vínculo con el consulado francés, ¡se creían españoles y se descubrieron en esa ocasión franceses! Sin embargo, tales confusiones no deben disimular la parte esencial ya que, como indica Tamar Herzog, es finalmente lógico que en la ausencia de una motivación específica, los extranjeros no hayan sentido la necesidad de clarificar precisamente cuál era su estatuto jurídico. Y, de hecho, en el caso estudiado, se puede admitir que hasta la Revolución francesa el hecho de ser avecindado o natural no cambiaba absolutamente nada la vida y las prácticas cotidianas de los mercaderes franceses que habían renunciado a la protección consular.

Al contrario, cuando había una rivalidad comercial o política importante, que implicaba saber precisamente a qué categoría pertenecía cada individuo, la situación se clarificaba. Así, el cónsul francés que conservaba cuidadosamente sus registros de matrículas, sabía muy bien quiénes eran los franceses colocados bajo su protección y los que no lo estaban, acordando su defensa sólo a los primeros ${ }^{16}$. De

\footnotetext{
14 Renaud Morieux considera que «los negociantes cambian de afiliación nacional con una extrema facilidad»y, a partir del caso de un negociante jugando con su doble nacionalidad, indica que «ese ejemplo demuestra una vez más que la definición de las identidades nacionales, como la de las prácticas ilícitas, varían según los locutores, los lugares y los momentos": Morieux, R.: Une mer pour deux royaumes. La Manche, frontière franco-anglaise $\left(X V I I^{e}-X V I I I^{e}\right.$ siècles), Rennes, PUR, 2008, pp. 340 y 341. Tras haber presentado casos similares, Jacques Bottin concluye que «lejos de ser excepcionales, esos casos subrayan la diversidad de trayectorias, el mestizaje cultural de esos migrantes, la percepción a veces borroneada de su identidad por la sociedad que les acoge y el carácter a menudo provisional de su instalación»: Botтin, J.: «La présence flamande à Rouen: l'hôte, l'auberge, la maison», en BotTIN, J. y CALABI, D. (dirs.): op. cit. (nota 8), p. 285. Catia Brilli también subraya que los mercaderes genoveses de Cádiz sacaban provecho de la ambigüedad de su estatuto de avecindado para reivindicar su condición de español o extranjero: BRILLI: op. cit. (nota 7), p. 97.

15 La Real Cédula de 8 de marzo de 1716, que instauró el estatuto de domiciliado (o avecindado) preveía el establecimiento de listas puestas periódicamente al día. Esa medida, nunca realizada, fue renovada en 1764 sin tener éxito: Enciso Recio, Leandro M.: «Actividades de los franceses en Cádiz (1789-1790)», Hispania, 19 (1959), pp. 264-265. En 1776, el cónsul francés en Cádiz deploraba de nuevo la voluntad del gobierno español de exigir que todos los extranjeros que cumplían con los criterios de avecindamiento fuesen excluídos del estatuto de transeúnte, y una nueva tentativa de establecer listas separando las personas entre los dos estatutos tuvo de nuevo lugar en 1780 Du BoIsrouvraY, Auguste: «La nation française à Cadix au XVIII ${ }^{\mathrm{e}}$ siècle», Revue des questions historiques, 1936, p. 182.

16 Sobre la protección ofrecida por el cónsul de Francia a sus compatriotas, ver: BartolomeI, Arnaud: «Les
} 
la misma manera, el Consulado de cargadores a Indias, encargado de proteger el monopolio de los españoles en el comercio colonial, permitía sólo a los individuos legalmente habilitados poder participar en la carrera de Indias. De hecho, no hemos encontrado, ni en la documentación oficial, ni en la prensa mercantil local, el caso de algún mercader francés que hubiera cargado abiertamente mercancías para las Indias cuando su estatuto no se lo permitía. Del mismo modo, cuando en 1793 y 1808 , los franceses fueron objeto de represalias, las reglas se aplicaron con el más absoluto rigor: en 1793 todos los transeúntes fueron expulsados de Cádiz, incluso los que intentaron hacer valer sus antiguos privilegios navarros o aquellos que ofrecieron dinero a cambio de quedarse. En 1808 se dieron algunos errores y ciertos españoles de origen francés fueron convocados por las autoridades urbanas, pero los casos litigiosos fueron rápidamente resueltos: los que poseían cartas de naturaleza fueron inmediatamente liberados y los demás fueron objeto de represalias, aunque se considerasen ellos mismos como españoles ${ }^{17}$.

Estos ejemplos demuestran que, cuando las situaciones lo imponían, la confusión y las dificultades de interpretación que eran comunes en las instituciones del antiguo régimen se atenuaban frente a una aplicación estricta, rigurosa y sensata de las leyes y de las decisiones de la corona. Resulta que, al menos en el Cádiz de finales del XVIII, es decir, en un lugar y en una época donde la cuestión de la extraneidad tenía una importancia crucial, los estatutos de los cuales se podían prevaler los extranjeros eran plenamente operatorios y ocupaban un papel decisivo en su práctica mercantil. El estudio del procedimiento de naturalización, que hemos podido reconstruir de manera detallada gracias a documentos en parte inéditos, demuestra que las autoridades eran plenamente conscientes de la importancia de esas cuestiones. Si las reglas de naturalización eran aplicadas con flexibilidad y tolerancia, los expedientes eran sin embargo examinados con mucha detención y las cartas de naturaleza no eran nunca concedidas a los individuos que no estaban en conformidad con las cualidades que la corona -y más generalmente la sociedad española-esperaba de un español.

\section{UN PROCEDIMIENTO DE NATURALIZACIÓN FORMALMENTE RI- GUROSO, PERO APLICADO CON DISCERNIMIENTO}

\subsection{Los criterios legales}

La literatura jurídica -y en primer lugar la Recopilación de las Leyes de Indias- define de manera extremadamente precisa los criterios formales que debían de cum-

\footnotetext{
relations entre les négociants français de Cadix et le pouvoir: comportements collectifs et stratégies individuelles (fin XVIII ${ }^{\mathrm{e}}$ siècle)», en Bertrand, Michel y PrIotTi, Jean-Philippe (dirs.): Circulations maritimes: l'Espagne et son empire (XVI ${ }^{e}$-XVIII ${ }^{e}$ siècle), Rennes, PUR, 2011, pp. 117-133.

17 Archivo Histórico Provincial de Cádiz (AHPC), Gobierno Civil, caja 3, expediente $n^{\circ} 11$, «Lista de los individuos franceses y de las otras naciones que le son agregadas, que no han venido al juramento de fidelidad» (1808) y caja 4 , exp. $n^{\circ} 7$, «Notas remitidas por los comisarios de barrios, expresivas de los naturales franceses quedados en esta ciudad, con distinción de su domicilio» (1809).
} 
plir los que solicitaban la obtención de una carta de naturaleza. El texto mismo de las cartas de naturaleza recoge incluso la lista de los criterios y los enfrenta uno por uno al expediente presentado por el pretendiente, lo que comprueba que el respeto de esos criterios eran, si no sistemáticamente exigidos -veremos que las posibilidades de dispensa son numerosas- al menos sí escrupulosamente examinados ${ }^{18}$. El conocimiento de las leyes y de su evolución, así como las referencias hechas en el texto de las cartas, atestigüan la precisión y el rigor con los cuales la administración legislaba: es el caso en el tratamiento del expediente de Pedro Pons, en el cual se hace referencia a una reforma del 30 de enero de 1775 que ha reducido el tiempo obligatorio de estancia en España ${ }^{19}$.

La nota siguiente (Documento 1), conservada casualmente entre los expedientes de naturalización tramitados a principios del siglo XIX por el Consejo de Indias, demuestra que los funcionarios encargados del examen de los expedientes debían recordar esos criterios y disponían de herramientas -en este caso una especie de plantilla- para deliberar en las mejores condiciones sobre cada caso.

18 A modo de ejemplo, reproducimos aquí amplios extractos de la carta de naturaleza concedida por el Consejo de Indias a Guillermo Estevan Bailleres: « ...que los expresados vuestros padres, abuelos y demás ascendientes por ambas líneas fueron cristianos viejos, limpios de toda mala raza, sin haber procesados por delitos que induzcan infamia ni ejercido oficios viles, ...como igualmente os habéis portado en el tiempo de vuestra residencia en la plaza de Cádiz a la que vinisteis al año 1764 y desde entonces habéis permanecido en ella, sin haber hecho ausencia notable, separado del fuero de vuestra nación como mi fiel vasallo, y a su consecuencia contrajisteis matrimonio en la propia ciudad de Cádiz el año de 1776 con Theresa Ghiselli, hija de don Roque Ghiselli y de doña Maria Rita de Mendoza, que aunque nacida y bautizada en Lisboa en el año de 1751 se crió y estableció en España, primero en la ciudad de Sevilla desde del año de 64, y después en Cádiz desde 1767, en compañía de sus padres, de cuyo consorcio habéis tenido varios hijos: que por lo mismo renunciasteis desde luego al Fuero de vuestra nación, sin asistir jamás a sus juntas, ni contribuir en las reparticiones a los gastos de ellas, satisfaciendo en la Aduana los reales derechos como si fueseis español sin haber disfrutado por razón de extranjero excepción ni privilegio alguno: que en 16 de abril 1792 comprasteis una casa principal situada en dicha ciudad en el callejón del tinte en precio de 300750 rs. [reales] von. [vellón] que con las mejoras posteriormente practicadas se ha aumentado considerablemente su valor, gravada solo con un tributo de 60235 reales 10 mvs. [maravedíes] von., que giráis por vos solo sin compañía alguna» (AGI, ID, leg. 1536, carta de naturaleza para comerciar con Indias, 3 de diciembre de 1795).

19 En la carta de naturaleza otorgada a Pedro Pons se recuerda que: «Las leyes prescriben que todo extranjero que quiera naturalizarse en estos aquellos Reinos deba tener 20 años seguidos de residencia, los 10 con casa, bienes raíces y casado con natural o hija de extranjero nacida en ellos, ascendiendo aquellos a la cantidad de 4000 ducados propios o adquiridos, cuyo término se halla reducido a 12 años por Real resolución a consulta del Consejo de 30 de enero de 1775» (AGI, ID, leg. 1536, carta de naturaleza para comerciar con Indias, 23 de diciembre de 1807). 
Documento 1: «Requisitos indispensables para adquirir los extranjeros cartas de naturaleza para comerciar con Indias» $(\text { sin fecha })^{20}$.

\begin{tabular}{|l|l|l|}
\hline 1 & Ley 31, libro 9, título 27 & Haber vivido en estos reinos, Indias o Islas 20 años continuos. \\
\hline 2 & Ley 31, libro 9, título 27 & $\begin{array}{l}\text { De estos 20 años deben haber sido los diez con casa y bienes raíces, y } \\
\text { casado con natural de estos reinos. }\end{array}$ \\
\hline 3 & Ley 32, libro 9, título 27 & Que la cantidad de bienes raíces debe ser de valor de 4000 ducados. \\
\hline 4 & Ley 31, libro 9, título 27 & $\begin{array}{l}\text { Estas circunstancias deben hacer las constar el Consejo de las Indias } \\
\text { con informaciones como se expresara. }\end{array}$ \\
\hline 5 & Ley 31, libro 9, título 27 & $\begin{array}{l}\text { Las justificaciones que se refieren deben hacerse en los pueblos donde } \\
\text { hayan residido los años de la ley y ante las audiencias con vista fiscal } \\
\text { si las hubiese y donde no ante la Justicia superior nombrando un fiscal } \\
\text { para su intervención. }\end{array}$ \\
\hline 6 & Ley 31, libro 9, título 27 & $\begin{array}{l}\text { Que habiendo consulado debe ser oído este para las alegaciones que } \\
\text { juzgue oportunas. }\end{array}$ \\
\hline 7 & Ley 31, libro 9, título 27 & $\begin{array}{l}\text { Que el juez que conozca de esta información debe poner su parecer en } \\
\text { ellas. }\end{array}$ \\
\hline 8 & Ley 32, libro 9, título 27 & $\begin{array}{l}\text { Que para justificar la cualidad de arraigado debe hacerse por escrituras } \\
\text { autenticas y no por informaciones. }\end{array}$ \\
\hline 9 & $\begin{array}{l}\text { Artículo 57, Real Cédula } \\
03 / 08 / 1801\end{array}$ & $\begin{array}{l}\text { Que no faltando ningunas de las circunstancias ante dichas debe pagar } \\
\text { el interesado el servicio de 8200 reales vellón. }\end{array}$ \\
\hline 10 & $\begin{array}{l}\text { Artículo 58, RC de } \\
03 / 08 / 1801\end{array}$ & $\begin{array}{l}\text { Cuando, faltase alguna de las cualidades en todo o parte se tratase de } \\
\text { dispensarle la Cámara regulara lo que deba aumentarse al expresado } \\
\text { servicio. }\end{array}$ \\
\hline
\end{tabular}

Los criterios para obtener una carta de naturaleza del Consejo de Castilla eran más flexibles que las exigidas por el Consejo de Indias, pero daban lugar a un examen igualmente detallado. Si estos criterios eran bien conocidos por los historiadores y han sido ampliamente comentados, se conocen menos las modalidades según las cuales eran aplicados y, finalmente, la importancia real que se les concedía. Sobre estos dos puntos, la documentación administrativa y privada que hemos consultado aporta elementos de respuesta particularmente esclarecedores, permitiéndonos entender mejor cuál era el recorrido administrativo de los expedientes previo a la decisión de los Consejos. Esto permite, en particular, un mejor conocimiento de los actores del procedimiento, las modalidades de examen de las demandas y los márgenes de maniobra que tenían las instancias decisorias para legislar sobre los casos particulares.

20 AGI, ID, leg. 1537, sin fecha. 


\subsection{Los actores del procedimiento}

Las cartas de naturaleza eran concedidas, en nombre del rey, por los dos Consejos de Indias y de Castilla. En el seno de los Consejos, las cartas de naturaleza seguían el procedimiento clásico, puesto que cada caso era presentado y defendido por el fiscal, que daba su opinión, y era zanjado por los jueces del Consejo, quienes decidían en última instancia. Los expedientes conservados en el Archivo de Indias permiten también un mejor conocimiento de las bases sobre las cuales los funcionarios madrileños tomaban sus decisiones: disponían de relevos acerca de los actores locales y, en este caso, era el presidente de la Casa de Contratación quien, en Cádiz, redactaba los memoriales preliminares depositados luego y discutidos ante el Consejo ${ }^{21}$. Por su lado, el Consejo de Castilla obtenía las informaciones que le eran útiles para deliberar del gobernador militar de la ciudad.

El hallazgo en los archivos provinciales de Cádiz, en el fondo privado de Miguel de Iribarren -un importante negociante español, miembro eminente del Consulado con cargos administrativos locales ${ }^{22}$, de fragmentos importantes de su correspondencia con el gobernador de la ciudad, permiten seguir acerca de quiénes y cómo el gobernador y el presidente de la Casa de Contratación se informaban ${ }^{23}$. En total, esas diferentes informaciones permiten reconstruir, en parte, la cadena jerárquica de actores que eran movilizados para la concesión de una carta de naturaleza (Documento 2).

Documento 2: Los actores de la naturalización en Cádiz a finales del siglo XVIII

\begin{tabular}{|c|c|}
\hline CARTA DE NATURALEZA & $\begin{array}{c}\text { CARTA DE NATURALEZA } \\
\text { CON LICENCIA }\end{array}$ \\
\hline Rey & Rey \\
\hline Consejo de Castilla & Consejo de Indias \\
\hline Gobernador de la Plaza & Presidente de la Casa de la Contratación \\
\hline Procurador Mayor & $?$ \\
\hline$?$ & $?$ \\
\hline
\end{tabular}

21 Tras la supresión de la Casa de Contratación en 1790, su último presidente fue remplazado por el Juez de Arribadas y Alzadas. El titular del empleo siguió siendo sin embargo Manuel Guiral y fue autorizado a conservar el título de "Presidente": MuÑoz Perez, José: «La supresión de la Casa de Contratación de Cádiz, 1790-1793», en Cádiz en su historia, II Jornadas de Historia de Cádiz, Cádiz, Caja de Ahorros de Cádiz, 1983, p. 122.

${ }_{22}$ Iribarren fue elegido procurador mayor - uno de los dos cargos electivos del cabildo de la ciudad-en 1782 y reelegido en 1783 y 1796. Desempeñó además la misma función de forma ínterina entre 1800 y 1802.

${ }_{23}$ La correspondencia entre Iribarren y el gobernador de la ciudad se conserva en un legajo denominado «Informes al Gobernador»: AHPC, Archivo Marqués de Villareal y Purullena, Fondo Miguel de Iribarren, leg. 55 (en adelante AHPC, Purullena, leg. 55). Agradecemos a Manuel Martín Ravina, director del archivo, el habernos llamado la atención sobre estos documentos. 
Por debajo de los informadores institucionales locales de los Consejos -el Gobernador y el presidente de la Casa de la Contratación- hay otros actores, con estatutos más o menos oficiales ${ }^{24}$, que estaban realmente en el origen de las informaciones trasmitidas. Estos últimos debían también tener sus propios informadores, pero las fuentes consultadas no son suficientemente precisas sobre esta cuestión. En realidad, se deduce de la lectura de la correspondencia privada de Miguel de Iribarren que es él, en la mayoría de los casos, quien estaba al origen de las informaciones. No deja de mencionar que conoce personalmente al individuo sobre el cual se le pide facilitar informes. En algunos casos, su conocimiento es relativamente impreciso - dice que lo conoce "de trato"- mientras que, en otros casos, menciona el tipo o la antigüedad de la relación que tiene con el pretendiente ${ }^{25}$. En otros casos dice haber recogido noticias seguras sobre el candidato y a menudo se contenta con evocar su reputación, es decir, la opinión general que se tiene de la persona en "el comercio de la ciudad" ${ }^{26}$. Casi siempre, en fin, Miguel de Iribarren da su opinión personal -su íntima convicciónsobre la candidatura.

Las informaciones tramitadas al gobernador son después consignadas en el informe que éste entrega al Consejo de Castilla. Puede darse el caso de que el expediente remitido sea considerado incompleto por el Consejo y que se pida al gobernador, respetando así la vía jerárquica, más precisiones que son luego repercutidas hasta el informador particular. Es el caso de Andrés Darhan, cuyo expediente fue tramitado con demasiada celeridad por Miguel de Iribarren en el primer examen. Este se había limitado a expresar un aviso muy favorable, basándose en la excelente reputación del pretendiente, y no se había molestado en proceder a un análisis de los criterios legales. El Consejo de Castilla hizo entonces saber que el expediente debía ser completado y que cada requisito legal debía tener su información correspondiente ${ }^{27}$.

Por lo tanto, a finales del siglo XVIII en Cádiz, el procedimiento legal de naturalización no era aplicado con ligereza y aparece, al contrario, muy escrupulosamente formalizado y respetado. Esa conclusión no nos lleva sin embargo a contradecir el concepto de naturalización implícita desarrollado por la historiadora Tamar Herzog en su investigación. En efecto, si los expedientes son formados con mucho rigor, son examinados luego con mucho discernimiento y lo que importa en la toma de decisión de los funcionarios no reside tanto en el respeto estricto de los criterios legales, sino en la apreciación general del nivel de integración de hecho en la sociedad local: esto

24 En realidad, la correspondencia que hemos consultado entre Miguel de Iribarren y los gobernadores Morla (1801-1803) y Solana (1803-1804) no coincide exactamente con el periodo durante el cual ejerció el cargo de procurador mayor interino (1800-1802). Eso significa que, a pesar de haber dejado sus cargos oficiales, Iribarren siguió siendo un informador privilegiado de los gobernadores sobre las cuestiones de naturalización y otras relativas al comercio de la ciudad.

${ }^{25}$ Usa la expresión «conocer de trato» a propósito de los individuos siguientes: Guilino Renete, Juan Pedro Daurel, Juan Pedro Covarrubias. Al contrario, menciona tener "un antiguo conocimiento de la casa Lecouteulx" en relación a la candidatura de Juan Bautista Lemoine, que fue socio de aquella casa, y dice tener un "antiguo conocimiento de su familia" cuando habla del caso de Jorge Butler. Por fin, dice haber tratado "de cerca por relaciones mercantiles" con Tomas Fleming y Simon Muchada: AHPC, Purullena, leg. 55, informes 47, 59, 63, 53, 69, 58, 66 (1803-1804).

26 Así, a propósito de Juan Pedro Daurel, que dice conocer «de trato», dice tener sus informaciones «según noticias hacendadas»: AHPC, Purullena, leg. 55, informe 59, 13 de noviembre de 1803. Para Tomas Fleming menciona que "todo lo expuesto he averiguado con exactitud": Ibidem, Informe 58, 23 de noviembre de 1803.

27 Ibidem, informe 49, 21 de octubre de 1803. 
es, la voluntad de permanecer, la sinceridad de su vínculo al país de acogida, la buena conducta y, en menor medida, la utilidad del sujeto.

\subsection{El examen de los expedientes}

Como se ha dicho, los Consejos deseaban la información más completa posible sobre los expedientes que tenían que examinar, y en particular sobre el cumplimiento de los requisitos legales. Sin embargo, cuando se analizan los expedientes que recibieron una respuesta favorable, aparece que los candidatos cumpliendo con todos los criterios son una minoría. Así, sobre 19 cartas concedidas por el Consejo de Indias a mercaderes franceses a lo largo del siglo XVIII y durante la primera década del XIX ${ }^{28}$, sólo 9 candidatos respetaban la totalidad de los requisitos, es decir, la renuncia a la protección consular del país de origen, el matrimonio con una española, una residencia en España de más de veinte años, la posesión de bienes raíces por un valor mayor a 4.000 ducados y la ausencia de asociación comercial con un negociante extranjero; en los otros $10 \mathrm{ca}-$ sos, al menos uno de los criterios no se cumple y ha necesitado de una dispensa. Entre estos últimos, en cinco ocasiones, el problema es menor, puesto que solo son los plazos por la posesión de bienes o el periodo transcurrido desde el matrimonio los que no son respetados. Sin embargo, en los otros 5 casos, la dispensa necesaria es más significativa: Francisco Borda y Pedro Bonnecase eran solteros y no poseían bienes raíces desde hacía mucho tiempo; Guilermo Baillères estaba casado con una extranjera y sus bienes raíces eran recientes; y finalmente, Fernando Roger y Juan Bonnemaison no tenían ningún bien raíz. Sin embargo, todos obtuvieron la autorización del Consejo mediante el pago de un derecho que, por su modestia, debe ser considerado como meramente simbólico ${ }^{29}$.

Si analizamos ahora las siete cartas de naturaleza concedidas a mercaderes franceses de Cádiz por el Consejo de Castilla, y que fueron registradas en los Libros de Actas capitulares del cabildo de la ciudad entre 1795 y $1798^{30}$, llegamos a conclusiones similares puesto que dos expedientes, al menos, presentan serios fallos ${ }^{31}$. Del mismo modo, los trece expedientes sobre los cuales Miguel de Iribarren fue consultado entre 1802 y 1804 -que no concernían esta vez únicamente a mercaderes franceses- ofrecen el mismo tipo de resultado. De hecho, si en ocho casos los requisitos se cumplen, en otros cinco los pretendientes no respetan todas las condiciones prescritas: Jorge Butler y Esteban Barron eran solteros, mientras que los franceses Simon Muchada y Juan Pedro Covarrubias y el genovés Guilino Renete no poseían bienes raíces ${ }^{32}$. Todos se vieron, sin embargo, gratificados al recibir un aviso tan favorable.

28 AGI, ID, leg. 1536.

29 Por ejemplo, Bernardo Darhan pagó 2.000 reales de vellón y Pedro Bonnecase 3.800 .

30 AMC, LAC, libros 151-154. Por desgracia no podemos precisar ni la frecuencia, ni el objetivo de tales registros que no eran aparentemente sistemáticos. Por ese medio, algunos naturalizados parecen haber deseado hacer pública la concesión de su carta de naturaleza.

31 Juan Mateo Lacosta y Juan Labargo eran solteros y no poseían bienes raíces: AMC, LAC, libro 151, f. 363,30 de octubre de 1795 y libro 154, f. 307, 6 de diciembre de 1798 .

32 AHPC, Purullena, leg. 55, informes 69, 42, 66, 63 у 47. 
¿Se debe entonces considerar que los criterios legales son irrelevantes y que no eran tomados realmente en cuenta? Esto tal vez sería una conclusión prematura, sobre todo si tenemos en cuenta los dos expedientes rechazados por no cumplir con demasiados criterios legales ${ }^{33}$; o cuando se considera que la inmensa mayoría de los expedientes cumplen a grandes rasgos con los criterios. Esto demuestra que los pretendientes sabían que sus expedientes serían examinados detenidamente y que no se atrevían a solicitar algo cuando pensaban no poder conseguir su pretensión. Los criterios no estaban exentos por lo tanto de valor, pero eran claramente secundarios en relación a una apreciación global del expediente que se centraba más precisamente en cuatro puntos que, aunque no aparecían nunca en la literatura jurídica oficial, eran de hecho realmente decisivos y eran objeto de la atención de los diferentes actores implicados en la tramitación de los expedientes: la intención real de radicarse en España, su sumisión a la corona, su "conducta" general y su "utilidad" para el país.

El vínculo con la corona constituye evidentemente un aspecto fundamental, al que las autoridades debían de aproximarse a través de los criterios legales del juramento y de la renuncia a la protección consular del país de origen. La cuestión de este vínculo es ampliamente tratada en los expedientes de los franceses, lo que no es de extrañar, dado el contexto conflictual que caracteriza las relaciones franco-españolas tras 1789: frente a las amenazas de guerra o de contagio ideológico, las autoridades españolas parecen temer más que nada la formación de una quinta columna enemiga en el seno de su población. Así que todos los elementos que pueden confirmar o reforzar la opinión formada por el análisis de los criterios legales son sistemáticamente mencionados ${ }^{34}$.

La intención de radicarse en España forma también parte de los elementos que importan en primer lugar a las autoridades españolas. De hecho, parece legítimo considerar, siguiendo a Tamar Herzog, que los criterios formales exigidos solo constituyen simples indicadores destinados a medir la realidad y la sinceridad de las declaraciones del pretendiente: al que estaba casado con una española, vivía en el país desde hacía varias décadas y poseía bienes raíces se le presumía tener la intención de instalarse. Las autoridades españolas parecían, sin embargo, ser conscientes de los límites de ese procedimiento: un individuo podía cumplir muy bien con los criterios legales, pero no haber abandonado el proyecto de regresar a su país. Por eso, las autoridades siempre buscaban otras informaciones sobre las motivaciones reales de los candidatos que cumplían con los requisitos legales, pidiendo por ejemplo a los informadores que les frecuentaban su íntima convicción sobre ese punto ${ }^{35}$. Del mismo modo, un

33 Se trata de la petición de Pedro Juan, soltero, sin bienes raíces de una cantidad ni de una duración suficientes. El fiscal dio un aviso favorable mediante el pago de un derecho de 8.000 reales de vellón, pero no obtuvo el acuerdo de los jueces: AGI, ID, leg. 1537, carta de la Cámara de Indias, 24 de enero de 1791. La petición de Juan Pedro Gastelu no cumplía ningún requisito y fue rechazada de esta forma: «no halla merito alguno para que se acceda a la referida solicitud que en su concepto debe depreciarse»: AGI, ID, leg. 1536, 12 de julio de 1806.

34 Por eso se detallan en las cartas de naturaleza informaciones como los donativos hechos por los pretendientes a la corona española, los esfuerzos consentidos por participar al esfuerzo bélico o su participación en una sociedad patriótica.

${ }_{35}$ Así, en los cuestionarios sobre los candidatos que el gobernador de Cádiz manda a Miguel de Iribarren le pregunta sobre la sinceridad de la voluntad del solicitante a radicarse y de expresar "lo demás que a VM se le ofrezca y parezca en punto a la referida solicitud". Tras enunciar las informaciones que dispone sobre el candidato, Iribarren 
individuo que no tenía todos los criterios legales podía pretender la naturalización si los informes redactados por los informantes le eran favorables. Este fue el caso de Juan Mateo Lacoste, cuyo expediente no dejaba evidenciar su intención de radicarse, puesto que era soltero y no posesía bienes raíces. La sinceridad de su demanda fue sin embargo medida usando otros criterios que, aunque no eran reconocidos oficialmente, permitían llegar a las mismas conclusiones ${ }^{36}$. Así, en el proceso de naturalización, la importancia de la apreciación global del expediente hecha por un observador con conocimiento personal y regular del pretendiente tenía un papel más importante que el respeto estricto de los criterios legales.

Igual de importante que la voluntad de radicarse, la buena conducta también era un punto esencial, a pesar de no reposar su apreciación en ningún criterio formal, y ser solamente tratada en los informes preliminares hechos por los informantes locales. Así, la reputación comercial es casi siempre evocada por Miguel de Iribarren, quien insiste no tanto en el nivel de riqueza -en la mayoría de los casos la fortuna del pretendiente es calificada simplemente de "decente" o de "regular"-, sino en su honestidad y en la confianza que inspira. Debía gozar de una "buena opinión" o hacer prueba de una "buena fe en su giro" y, si ha sufrido una quiebra, se precisaba que esta era "excusable", debido a la situación general de la plaza ${ }^{37}$. Sin embargo, la reputación comercial no era suficiente y, según el origen del pretendiente, el examen se hacía sobre sus prácticas religiosas o sobre sus opiniones públicas. No es de extrañar que este último aspecto tenga una importancia particular en la evaluación de los expedientes de los franceses tras el estallido de la Revolución. En el caso de Andrés Darhan se dice que nunca ha hecho "uso de la cucarda", y en cuanto a Juan Mateo Lacoste, se precisa que tiene una "conocida desafección a los actuales sistemas perniciosos de la Francia". Del mismo modo, el haber estado en Marruecos o en los Estados Unidos -antes que en Francia-, durante la guerra de la Convención, fue considerado como un elemento a favor en el caso de los expulsados en 1793, así como el pertenecer a una familia de nobles emigrados ${ }^{38}$. Para los irlandeses -detrás de los cuales siempre estaba la sospecha de que en realidad pudieran tratarse de ingleses- las autoridades se focalizaban en las prácticas religiosas, según los cuestionarios enviados por el gobernador a Miguel de Iribarren. Éste nunca dejaba pasar una ocasión de mencionar que había visto personalmente a los pretendientes "concurrir a los actos de nuestra Santa Religión" 39 o que sabía por voz pública que practicaban notoriamente la religión

le contesta: "Con estos fundamentos, lo contemplo con ánimo de permanecer en España por el tiempo de su vida": AHPC, Purullena, leg. 55, informe 49.

${ }^{36}$ Los elementos valorizados en su carta de naturaleza eran el hecho de que su familia fuese claramente hostil al régimen político francés (puesto que había tenido que emigrar) y que sus hermanos estaban bien integrados en Jerez, donde tenían una compañía de exportación de vinos y ya habían conseguido también ellos la naturaleza: AMC, LAC, Libro 151, f. 363, 30 de octubre de 1795.

37 A propósito de la quiebra sufrida por Juan Pedro Covarrubias en 1798, se dice que ha sido causada "por las vicisitudes del comercio": AHPC, Purullena, leg. 55, informe 63.

38 Por Andrés Darhan: AHPC, Purullena, leg. 55, informe 49. Para los demás informes, todos relativos a Juan Mateo Lacoste: AMC, LAC, Libro 151, f. 363.

${ }^{39}$ AHPC, Purullena, leg. 55, informe 38, "Solicitud e informe sobre la naturaleza en estos Reinos de Juan Roberts y Enrique Dowel, irlandeses (1802)". 
católica ${ }^{40}$. El hecho de ser miembro de una cofradía de la ciudad era particularmente tenido en cuenta, algo que por supuesto no ignoraban los mismos pretendientes a la naturalización. Ya hemos tenido la ocasión de demostrar que prácticamente la totalidad de los mercaderes de origen francés afiliados a la cofradía del Santísimo Viático, apadrinada por Manuel Guiral, presidente de la Casa de Contratación, quien tenía un papel tan importante en el proceso de habilitación al comercio colonial, eran individuos recientemente naturalizados, o a punto de serlo, o bien jenízaros solicitando su habilitación ${ }^{41}$. La buena conducta suponía, en definitiva, dos condiciones por parte del pretendiente: por un lado, participar plenamente y abiertamente en la vida pública local, tanto en el comercio -frecuentando por ejemplo las sesiones diarias de la bolsa- como en las sociabilidades urbanas, asistiendo a los actos religiosos o a las fiestas. Por otro lado, se esperaba que su comportamiento fuera, en estas ocasiones, conforme al de los demás españoles. En todo caso, era la integración del individuo dentro de la sociedad local lo que se apreciaba, utilizando para eso el recurso a la reputación del individuo, lo que podemos considerar aquí como una auténtica herramienta de control social de los individuos, usada abiertamente por los informantes en sus informes.

Finalmente, la utilidad del pretendiente para el país era considerada como un criterio importante, lo que no tiene nada de sorprendente al considerar que la administración seguía impregnada por la ideología mercantilista ${ }^{42}$. No se debe sin embargo exagerar la importancia del nivel de riqueza del candidato: naturalmente es evaluado y valorizado cuando el caso se presenta ${ }^{43}$, pero no constituye en ningún caso un criterio decisivo. Se ha podido observar con los varios casos de individuos que se han beneficiado de un informe muy favorable por parte de Miguel de Iribarren, aunque su capital sólo fuese considerado como "decente" o "regular". El interés general del individuo para el país es lo que más importa. Esto explica la atención particular que reciben las asociaciones comerciales en las cuales los pretendientes están implicados y la evaluación que se hace de la autonomía que mantienen respecto a los intereses extranjeros: se debe a toda costa evitar que los beneficios sacados de las actividades mercantiles sean extraídos del país ${ }^{44}$. El hecho de poseer una fábrica que permitía vi-

\footnotetext{
${ }^{40}$ A propósito de Jorge Butler, Miguel de Iribarren dice "este y toda la familia son católicos y ejercen públicamente los actos religiosos": AHPC, Purullena, leg. 55, informe 69, 29 de octubre de 1804

41 BARTolomei, Arnaud: "Le marchand étranger face à la crise: départ ou intégration? Le cas de la colonie française de Cadix aux époques révolutionnaire et impériale", en BuRKARDT, A. (dir.): Commerce, voyage et expérience religieuse, XVIe-XVIIIe siècles, Rennes, PUR, 2007, pp. 489-490.

42 Así lo demuestra este extracto del expediente de naturalización de cuatro viticultores importantes de Jérez: Juan Pedro, Juan Luis y Juan Carlos Haurie y Pedro Lembeye: "Todas las Naciones comerciantes e industriosas cuidan mucho de atraer a si los capitales extranjeros para aumentar el suyo, por que reconocen el principio de que la agricultura, Industria y Comercio de un país no pueden prosperar sino en razón de su capital aplicable a estos ramos, y por consiguiente lejos de excluir a los Extrangeros industriosos debe excitárseles con la indulgencia para que contribuyan con sus fondos a los progresos de nuestra industria y comercio": AGI, ID, leg. 1536, "Informe sobre la solicitud de que se les conceda carta de naturaleza para comerciar en Indias", 2 de junio de 1807.

43 A propósito de la solicitud de Prudent Delaville, se recuerda que posee "un caudal tan quantioso que se reputa por el más opulento del País" y en la de Luis de Rivera se precisa que es uno "de los sugetos de mayor caudal y mejor credito de aquel comercio": AGI, ID, leg. 1536, cartas de naturaleza, 27 de enero de 1793 y 4 de febrero de 1792.

44 Es por estar asociado a un francés llamado Juan Baillères que la primera solicitud de naturalización de Bernardo Lasaleta fue rechazada en 1786, y que su hijo, Josef Eugenio, no pudo obtener su habilitación en calidad de jenízaro. Las dos pretensiones fueron finalmente atendidas después de que los corredores de la ciudad certificasen
} 
vir a varias familias era también un criterio positivo ${ }^{45}$; o también el practicar una actividad mercantil basada en la exportación de las riquezas locales, como lo ilustran los casos de Enrique Dowel, los hermanos Haurie o Juan Mateo Lacoste, todos al frente de bodegas jerezanas ${ }^{46}$. Si la riqueza y la utilidad eran elementos favorables a ojos de las autoridades, no eran sin embargo suficientes. Cuatro negociantes franceses tuvieron esta cruel experiencia puesto que, a pesar de ser muy ricos y de haber ofrecido cantidades importantes para obtener su naturalización y tratar de evitar así su expulsión en 1793, sus demandas, consideradas como oportunistas, fueron rechazadas ${ }^{47}$.

Los criterios exigidos para la obtención de la naturalización no eran absolutos, permitiendo evaluar directamente sobre la pretensión, pero tampoco facultativos, siendo difíciles las dispensas. En realidad, los requisitos eran utilizados como pretexto para una investigación más detallada sobre la personalidad del pretendiente, la sinceridad de sus motivaciones y su integración real dentro de la sociedad local. A la luz de esta constatación, el proceso de naturalización de los extranjeros aparece finalmente como una institución eficaz: es lo suficiente abierta como para permitir a todo extranjero integrado de hecho en la sociedad española su acceso a la naturalización; pero lo suficientemente rigurosa como para evitar que los individuos, animados por motivaciones estrictamente oportunistas, lo puedan conseguir. Esto nos lleva a retomar el problema planteado en la introducción a esta contribución y nos permite sugerir algunas pistas de reflexión para resolverlo: ¿Cómo interpretar la actitud de los mercaderes franceses que se habían mantenido alejados de la naturalización a lo largo del siglo XVIII y que la solicitaron en número significativo a partir de la Revolución?

\section{LA ACTITUD DE LOS MERCADERES FRANCESES DE CÁDIZ FRENTE A LA NATURALIZACIÓN}

El número de casos conocidos de mercaderes franceses que obtuvieron la naturalización en Cádiz antes de la Revolución francesa es muy reducido. Los fondos del Archivo General de Indias que contienen, en teoría, la totalidad de las cartas de naturaleza con licencia para comerciar en Indias, sólo conservan cuatro cartas concedidas a negociantes franceses a lo largo del siglo ${ }^{48}$, lo que es mucho menos que otras comunidades extranjeras de la ciudad ${ }^{49}$. A pesar de no poseer la misma información

\footnotetext{
la disolución de la compañía en 1788 y tras el fallecimiento de Juan Baillères en 1789: AGI, ID, leg. 1536, carta de naturaleza, 16 de julio de 1790 y leg. 1537, "Expediente sobre concesión de carta de naturaleza a Don Josef Eugenio Lassaleta del comercio de Cádiz” (1790).

45 Se precisa así que Pedro Bonnecase a invertido "crecidos fondos en la Real fábrica de pintados de Chiclana", que permitía vivir a 200 familias: AGI, ID, leg. 1536, carta de naturaleza, 12 de marzo de 1807.

46 Para Dowel: AHPC, Purullena, leg. 55, informe 38; para los demás: notas 42 y 36.

47 Se trata de Juan Bonneval, Bernardo Magon, Tomas Gervinais y Diego Jugla que ofrecieron, en 1793, 100.000 reales para obtener su naturalización. Los jueces del Consejo Extraordinario encargados de deliberar sobre la solicitud consideraron que "solo el temor de verse privados de sus bienes en virtud del embargo que mandaban dichas Provisiones, les movió a pedir la gracia de naturaleza" y la rechazaron: Archivo Histórico Nacional, Consejos, leg. 6349, informe del 3 de junio de 1793 .

48 Se trata de Pedro Lassaleta (1768), Juan Francisco Puyade (1772), Pedro Luceta (1777) y Pedro Goin y Martel (1778): AGI, ID, leg. 1536.

49 Ver nota 2.
} 
para las cartas tramitadas por el Consejo de Castilla, se puede destacar que solamente cuatro mercaderes matricularon sus cartas de naturaleza en los libros capitulares del cabildo de Cádiz ${ }^{50}$. Estas cifras parecen por lo tanto confirmar el poco interés que para los mercaderes franceses tenía la naturalización española, quienes gozaban además, gracias a su estatuto de transeúnte, de varias ventajas y privilegios.

Esta interpretación es, sin embargo, insuficiente si se considera que un número importante de mercaderes franceses que ejercían en el comercio de Cádiz tenían en realidad el estatuto de avecindado, lo que significa que no estaban matriculados en los registros del consulado de Francia y no podían por lo tanto beneficiarse de su protección. Calcular su número resulta muy difícil, puesto que las autoridades españolas, hasta el censo de 1791, nunca han conseguido establecer listas sistemáticas y regularmente puestas al día de los extranjeros avecindados. Podemos sin embargo arriesgarnos a adelantar algunas consideraciones teniendo en cuenta, por un lado, que un tercio de los mercaderes franceses matriculados en 1791 -o sea un centenar-, confrontados a la obligación de elegir entre los dos estatutos, se declararon como avecindados. Por otro lado, más de la mitad de los individuos matriculados en 1791 que declararon residir en España desde hacía más de quince años, no aparecían en la lista consular de 1777, encontrada y estudiada por Didier Ozanam en su famoso estudio dedicado a la colonia francesa de Cádiz ${ }^{51}$. Esos datos son muy aproximativos: mercaderes franceses transeúntes en los años 1780 pudieron declararse domiciliados en 1791, y las declaraciones hechas en 1791 concernían el tiempo pasado en España y no en Cádiz, lo que puede explicar muchas de las ausencias constatadas en la comparación con la lista de 1777. Sin embargo, a pesar de ello, son informaciones útiles que permiten dar un orden de tamaño sobre la importancia que podían representar ese grupo de mercaderes franceses que no solicitaba la protección consular. Ahora bien, ¿cómo interpretar su elección? ¿Debemos considerarla como una prueba más del famoso "doble juego" que se asocia generalmente a los negociantes extranjeros, acusados de hacer valer una u otra de sus identidades múltiples en función de la necesidad del momento? Esto nos parece poco pertinente puesto que, de hecho, los mercaderes franceses avecindados perdían las ventajas de la protección ofrecida por el consulado y los tratados franceses, sin conseguir por lo tanto el único privilegio español que les hubiera podido ser útil: la autorización para comerciar con Indias. Por carecer de un motivo claramente identificado, debemos aceptar la consideración de su actitud como sincera y desinteresada: esos negociantes ya no tenían intereses comunes con Francia $\mathrm{y}$, por tratarse en la mayoría de los casos de tenderos o de pequeños comerciantes, no tenían tampoco realmente necesidad de la protección consular que beneficiaba sobre todo a la élite mercantil implicada en el comercio del peso de plata. ¿Por qué entonces no solicitaban la naturalización española? Parece inútil desarrollar aquí una cuestión ampliamente tratada por Tamar Herzog: eso no hubiera cambiado para nada su vida cotidiana, por estar muy cerca las condiciones de natural y de vecino. Además mu-

50 Se trata de Dionisio Duque (1724), Pedro Membielle (1764), Pedro Luceta (1764) y Juan Francisco Puyade (1765): AMC, LAC, libros 80, 111, 120 y 121.

51 Ozanam, D.: "La Colonie française de Cadix au XVIII ${ }^{\mathrm{e}}$ siècle", Mélanges de la Casa Velázquez (1968), p. 259-347. 
chos se consideraban, ciertamente y con toda sinceridad, como auténticos españoles e ignoraban muy probablemente que existía un procedimiento legal para hacerse español, lo que explica la sorpresa de muchos de ellos cuando fueron convocados como franceses en el censo de 1791.

La Revolución francesa no cambió radicalmente la situación de los negociantes franceses en Cádiz, al menos en un primer momento. El censo de 1791 obligaba a cada uno a precisar y a oficializar su estatuto jurídico, pero, como los mercaderes franceses habían sido exentos de las medidas de expulsión que azotaron a los demás transeúntes de la Península, eligieron globalmente el estatuto que correspondía más a su situación real: los que estaban integrados desde hacía mucho tiempo en la sociedad local y que no tenían más relaciones con el consulado de Francia eligieron en su gran mayoría el estatuto de domiciliado, mientras que los que habían vivido siempre bajo la protección consular confirmaron esa elección optando por el estatuto de transeúnte, probablemente tras una deliberación colectiva. Cuando dos años más tarde estalló la guerra de la Convención, los primeros fueron autorizados a quedarse en Andalucía y los segundos fueron expulsados. Al final de la guerra, la colonia francesa se reconstituyó sobre las mismas bases que las del siglo XVIII, con una mayoría de transeúntes, organizados en "nación" -llamados en adelante "factoría"- bajo la autoridad de un cónsul, y una minoría integrada en la sociedad local.

Sin embargo, a medio plazo la Revolución sí que cambió las cosas, tanto para unos como para otros, y de forma más profunda de lo que parece. No es este el lugar para extenderse sobre el nuevo contexto político que contribuyó fuertemente a reforzar el sentimiento nacional de los franceses transeúntes, que tomaron la costumbre mucho más que en el antiguo régimen de afirmar y reivindicar su identidad francesa y su fidelidad hacia los sucesivos regímenes que florecieron al norte de los Pirineos ${ }^{52}$. Por su lado, los franceses integrados se encaminaron mucho más que antes hacia la naturalización legal. Todos los indicadores coinciden en efecto en sugerir que el número de demandas -y de concesión- de cartas de naturaleza, presentadas ante el Consejo de Indias y el Consejo de Castilla, aumentaron muy sensiblemente. Esto no deja ninguna duda en el primer caso puesto que se puede comparar sin lugar a dudas el número de cartas otorgadas antes de la Revolución (cuatro) y después (quince) ${ }^{53}$. En lo que respecta a los procesos de naturalización despachados por el Consejo de Castilla, sólo tenemos informaciones parciales, pero todos coinciden: el número de cartas registradas en los libros capitulares del cabildo pasan de cuatro (antes de 1789)

52 El ausentismo manifestado por los negociantes franceses de Cádiz en sus "asambleas de la nación”, sobre todo cuando éstas no tenían otra función que la de manifestar la fidelidad de la colonia a la monarquía, demuestra la distancia creciente al final del antiguo régimen entre el mundo de los negocios y la corona francesa: BARTOLOMEI: op. cit. (nota 41), pp. 486-488. Jean-François Labourdette hace la misma constatación en Lisboa: LABOURDETTE, J.F.: La nation française à Lisbonne de 1699 à 1790. Entre colbertisme et libéralisme, París, 1988. Al contrario, la Revolución y el advenimiento del nuevo régimen provocaron una reacción entusiasta en la colonia francesa de Cádiz: el mejor ejemplo es el éxito que tuvo el "donativo patriótico" ofrecido en 1790 a la Asamblea Nacional, y al que participaron todos los negociantes de la ciudad, con la excepción de tres (Delaville, Béhic y Verduc): Centre des Archives Diplomatiques de Nantes, Cadix, registre 258, fol. 118, 21/04/1790. De forma más general, sobre la acogida de la Revolución en el seno de la comunidad francesa, ver ENCISO ReCiO: op. cit. (nota 15).

53 AGI, ID, leg. 1536. 
a ocho ${ }^{54}$. Además, para los años 1802-1804, cubiertos por la correspondencia de Miguel de Iribarren, al menos cinco expedientes de naturalización fueron examinados por el Consejo de Castilla y casi la mitad concernían a franceses ${ }^{55}$. En fin, durante los varios censos de "naturales franceses" que se hicieron en las represalias de 1808 y 1809 , nada menos que veinte y tres individuos convocados por las autoridades exhibieron cartas de naturaleza, mientras se sabe que no todos los naturalizados fueron evidentemente convocados ${ }^{56}$.

Una vez más, la interpretación de una inclinación repentina por la naturalización está mal planteada, tanto como la cuestión del supuesto oportunismo que motivó las demandas. En efecto, el estudio del perfil de esos individuos naturalizados no indaga nada en esa dirección: en casi todos los casos, la naturalización aparece como la última etapa lógica de una trayectoria de integración iniciada mucho antes de la Revolución, con la ruptura con el cónsul de Francia. Por lo tanto, los acontecimientos del periodo revolucionario no modificaron las trayectorias de los negociantes franceses y solo llevaron a varios de ellos a poner su estatuto en conformidad con la realidad de su situación social ${ }^{57}$.

Queda por resolver una última cuestión: ¿por qué no hubo más solicitudes de naturalización durante este periodo? De hecho, aunque sí que hubo una elevación significativa del número de naturalizaciones a partir de 1789, los negociantes franceses que lo solicitaron quedaron muy minoritarios (dos o tres decenas sobre un total aproximativo de trescientos individuos), aunque la composición social de la colonia había cambiado fuertemente a finales de siglo. El porcentaje de individuos con varios años de residencia en España, casados con españolas o que poseían bienes raíces efectivamente había aumentado bastante, y por lo tanto muchos son los franceses que hubieran podido obtener ahora sin dificultad la naturalización. Además fue suprimido entonces el estatuto de domiciliado por las autoridades españolas y los negociantes franceses que estaban bien integrados a la sociedad local y que habían optado por su avecindamiento en 1791, tenían que elegir desde ahora entre el estatuto de transeúnte y el de naturalizado ${ }^{58}$. Pero, a pesar de todo eso, no hubo ninguna riada hacia la naturalización en el seno de la colonia. Parece necesario, una vez más, renunciar a toda explicación basada en una interpretación estrictamente oportunista de la actitud de los mercaderes franceses. Casi todos los negociantes que solicitaron entonces su naturalización cumplían los criterios necesarios, tanto los oficiales como los oficiosos, para pretender la naturalización. Las excepciones eran muy $\operatorname{raras}^{59}$. No había, ade-

${ }^{54}$ AMC, LAC, libros 149-154.

55 AHPC, Purullena, leg. 55.

56 AMC, libros 6973-6975, "Juramento de fidelidad de los nacionales franceses" (1808) y AHPC, Gobierno Civil caja 3, expediente $n^{\circ} 11$, y caja 4 , expediente $n^{\circ} 7$ (para las referencias completas ver nota 17).

57 Es lo que constata, por ejemplo, el agente consular francés de Sevilla cuando informa, en 1791, a propósito de dos negociantes franceses de la ciudad que "malgré toutes mes exhortations, ils se sont naturalisés. Ils couraient au devant de la séduction, et depuis longtemps il était public qu'ils n'attendaient que l'occasion pour déclarer leurs intentions". Archives Nationales, serie AE BIII, registro 362, carta del 10 de septiembre de 1791.

58 Real Orden de 28 de julio de 1807, reproducida integralmente en los libros de actas capitulares de Cádiz: AMC, LAC, libro 154, fol. 509, 12 de septiembre de 1807.

59 El caso de Prudent Delaville constituye una excepción particularmente interesante: al contrario de todos los demás naturalizados, nunca había cortado con el cónsul de Francia antes de la Revolución y participaba activamente 
más, ninguna razón objetiva para que mercaderes franceses que se habían mantenido alejados de la protección consular en el siglo XVIII, cuando era realmente ventajosa, la solicitasen en una época en la cual las relaciones entre Francia y España eran más que nunca imprevisibles. También se puede descartar la hipótesis según la cual, a partir de 1789, hubo un endurecimiento de las condiciones de acceso a la naturaleza española para los franceses, cuando en el peor de los casos sólo se tuvo una atención mayor a sus opiniones políticas. Los numerosos expedientes tratados con suavidad por las autoridades son suficientes para probar que, hasta el estallido de la guerra de la Independencia, ese endurecimiento no se produjo. Sin embargo, no es de extrañar que la guerra contra Napoleón sí que llevó a una suspensión de los procesos de naturalización en curso y, de forma más general, a una mayor desconfianza hacia los franceses ${ }^{60}$.

La única explicación que parece por lo tanto adecuada para explicar el poco apremio de los franceses en solicitar la naturalización española es la afección a la identidad nacional francesa. No ignoramos, evidentemente, las reticencias que produce el uso del concepto de "identidad nacional" para este periodo ${ }^{61}$. Sin embargo, parece difícil no recurrir a este sentimiento en este caso. Varios indícios sugieren en efecto que, mucho antes de la Revolución francesa, el sentimiento de pertenencia a una nación distinta, por su cultura, sus costumbres y su ideología, estaba ampliamente difundido entre los negociantes franceses ${ }^{62}$. La Revolución contribuyó a la cristalización de esa conciencia identitaria, radicalizándola de modo que tuvo que reforzar el sentimiento de los franceses de pertenecer a una nación extranjera incluso entre los que estaban objetivamente integrados en la sociedad local y que no mantenían desde hacía ya mucho tiempo relaciones con el cónsul de su nación. Los franceses que no optaron por la naturalización debieron resentir esa decisión cuando, en 1808, una amplia represión se abatió sobre todos los que residían en la ciudad, lo que llevó a una mayoría de ellos a prestar juramento de fidelidad a Fernando VII. El oportunismo, en este caso incuestionable, no pasó desapercibido por las autoridades españolas, que impusieron medidas de represalias sobre todos los franceses que no podían valerse

en las "asambleas de nación". Su cambio parece haber sido motivada por razones ideológicas, como lo prueba el hecho de que no participara al donativo patriótico de 1790 o que acogiese poco después a un cura refractario huido de Francia.

60 El expediente de naturalización de Juan Pedro Irigoyen fue suspendido, entre 1809 y 1811, por motivo de una Real Orden de 25 de mayo de 1810 que instaba a que mientras "dure la guerra actual no se expidan cartas de españolización a los naturales de Francia": AGI, ID, leg. 1536, "Informe sobre concesión de carta de naturaleza para comerciar con Indias", 11 de septiembre de 1810. De forma más general, el juramento de fidelidad a Fernando VII que prestaron 179 comerciantes de Cádiz en 1808 fue considerado sin valor, y no impidió que los que juraron escapasen a las represalias decretadas contra ellos en 1809: BARTOLOmeI, Arnaud: "Des biens aux personnes. Les représailles exercées contre les marchands français de Cadix dans les conflits franco-espagnols des périodes révolutionnaire et impériale (1793-1815)", Mélanges de la Casa de Velázquez, 39-1 (2009), pp. 176 y siguientes.

${ }_{61}$ Entre las posiciones firmes adoptadas recientemente, ver: Jean-Frédéric ScHAUB: "Le sentiment national est-il une catégorie pertinente pour comprendre les adhésions et les conflits sous l'Ancien régime?", en TALlON, A. (dir.) Le sentiment national dans l'Europe méridionale aux XVI et XVII siècles, Madrid, Casa de Velázquez, 2007, pp. $155-165$.

62 Bartolomer, Arnaud: "Identidad e integración de los comerciantes extranjeros en la Europa moderna. La colonia francesa de Cádiz a finales del siglo XVIII", en CRespo SolanA, A. (dir.): Comunidades transnacionales. Colonias de mercaderes extranjeros en el Mundo Atlántico (1650-1830), Madrid, Ediciones Doce Calles, 2010, pp. $370-372$. 
de una carta de naturaleza en su debida forma. Este último episodio demuestra que toda lectura unívoca de la actitud de los mercaderes franceses debe ser descartada, puesto que estos últimos no dudaron, sin éxito, a renunciar a su fidelidad a su país de origen para salvaguardar sus intereses particulares del momento. Sin embargo, esto no debe hacer olvidar que durante varias décadas, decenas de mercaderes franceses que no sacaban ningún interés de su estatuto de extranjero, se negaron a solicitar la naturalización española, aunque cumplían con todos los requisitos para hacerlo.

\section{CONCLUSIÓN}

Finamente pueden sacarse dos conclusiones de nuestra investigación sobre los usos que hicieron el estado español, por un lado, y los mercaderes franceses de Cádiz, por el otro, del proceso de naturalización a finales del siglo XVIII y principios del XIX.

Por lo que respecta al Estado, nuestro trabajo confirma de forma innegable las conclusiones sacadas por Tamar Herzog en su estudio sobre los mecanismos que acompañan y sostienen el proceso de naturalización en España. Más que el cumplimiento de criterios formales, lo que más aprecian las autoridades es el nivel de integración efectivo en la sociedad española. Para ello, los extranjeros que solicitaban la naturalización eran sometidos a auténticas encuestas de moralidad para determinar, más allá de las apariencias, cuáles eran sus verdaderas intenciones, la sinceridad de su solicitud y la integración efectiva en una de las comunidades que les acogían. Como regla general, si el pretendiente gozaba de una buena reputación y participaba abiertamente en la vida social de sus conciudadanos, obtenía sin ninguna dificultad de los agentes locales los informes favorables que le abrían el acceso a la naturaleza española. Si ese acceso parece finalmente relativamente fácil, sin embargo no hay que confundir la relativa liberalidad del estado español con cualquier debilidad o ingenuidad en la materia: los extranjeros que intentaban abusar del protocolo para su provecho, solicitando el acceso a un estatuto que sus compromisos y sus prácticas sociales contradecían, eran rechazados. El número reducido de expedientes rechazados demuestra la conciencia que tenían los contemporáneos de los requisitos que se tenían que cumplir para hacerse español: los que sabían que se comportaban como extranjeros y que eran conscientes por lo tanto de ser percibidos como tales, sabían también que tenían pocas posibilidades de conseguir la naturalización y debían probablemente abstenerse de presentar su solicitud. En definitiva, el proceso de naturalización, ofreciendo un acceso fácil a los extranjeros integrados y disuadiendo los comportamientos oportunistas de los que querían jugar a dos bandas, parece finalmente haber dado buenos resultados.

Si pocos mercaderes franceses fueron naturalizados en Cádiz, no es por lo tanto porque el procedimiento se lo prohibía, sino porque entre ellos se daba poca inclinación por ese estatuto. En efecto, durante la mayor parte del siglo XVIII, la mayoría de los negociantes franceses de Cádiz, que habían cortado sus relaciones con el cónsul de su nación y que dejaron así de beneficiarse de su protección diplomática, no buscaron por lo tanto la obtención de una naturalización formal. Eso se explica por 
el hecho de que un reconocimiento formal carecía de interés para ellos. Cuando, tras la Revolución, ese reconocimiento se hizo más importante, y que ser formalmente reconocido como francés o español dejó de ser una cuestión secundaria, numerosos mercaderes franceses se preocuparon en solicitar una carta de naturaleza y, en la gran mayoría de los casos, la consiguieron. Sin embargo, a pesar del contexto de crisis, la mayoría de los comerciantes franceses, incluidos los que estaban perfectamente integrados en la sociedad local, se negaron a proceder como los demás, quedándose fieles a su identidad, o a su estatuto, de "francés". A modo de conclusión, acabaremos con esta última pregunta: los franceses que no quisieron naturalizarse, ¿tenían acaso apego a su identidad francesa o a los derechos a ella asociados? En el estado actual de nuestros conocimientos, no podemos zanjar este punto. Sin embargo, estamos en medida de poner en cuestión la idea, muy extendida entre la historiografía reciente, que considera como una evidencia el hecho de que los mercaderes de la época moderna se movían por una única búsqueda de sus intereses económicos inmediatos, totalmente desprovistos de conciencia política, religiosa, cultural o moral a la hora de tomar sus decisiones. 